\title{
AS RELAÇÕES ENTRE O SINGULAR E O GERAL NA PRECARIZAÇÃO DAS CONDIÇÕES DE TRABALHO DA EDUCAÇÃO FÍSICA NA ESCOLA
}

\author{
Isabella Filippini* \\ Giovanni Frizzo**
}

\section{RESUMO:}

O objetivo deste texto é aprofundar a análise acerca da precarização das condições de trabalho da Educação Física (EF) na escola. Através de um estudo de caso realizado nas escolas municipais de Nova Santa Rita, buscamos desenvolver a relação entre o singular e o geral, pela via da mediação particular, para compreender a realidade do fenômeno em sua totalidade, em relação à atividade do professorado de EF na escola e as determinações recíprocas com o modo de produção da existência.

Palavras-chave: Educação Física. Condições de Trabalho. Escola.

\section{INTRODUÇÃO}

O presente texto se origina de uma pesquisa mais ampla denominada: "A Organização do Trabalho Pedagógico da Educação Física (EF) na Escola Capitalista", desenvolvida sob a forma de um estudo de caso na Rede Municipal de Ensino de Nova Santa Rita (RMENSR) e que teve como objeto de investigação a organização do trabalho pedagógico da EF nas séries finais do ensino fundamental. Orientados pelo seguinte problema: "como se organiza o trabalho pedagógico e o trato com o conhecimento da EF na escola capitalista e que relações estabelecem com o desenvolvimento das forças destrutivas do sistema do capital na atualidade?", realizamos o trabalho de campo durante todo o ano letivo escolar de 2010 utilizando como instrumentos de coleta de informações, a análise de documentos, a observação participante nas seis escolas municipais que oferecem as séries finais do ensino fundamental (com a confecção de um Diário de Campo), entrevistas semiestruturadas com o professorado de EF (8 professoras e professores) e questionários com perguntas abertas e fechadas para o alunado (respondido por 305 estudantes).

Desta investigação, sistematizamos algumas categorias que nos

\footnotetext{
" Mestranda em Educação Física pela UFPel, professora da rede estadual de ensino do Rio Grande do Sul.

** Doutor em Ciências do Movimento Humano pela UFRGS, bolsista FAPERGS/CAPES.
} 
possibilitaram elencar diferentes elementos para contribuir na elaboração da teoria pedagógica. Dentre estas categorias, fizemos um recorte que apresentamos neste texto, com o objetivo geral de aprofundar a análise acerca da precarização das condições de trabalho da EF na escola, articulando aspectos singulares oriundos das atividades do professorado de EF nesta rede de ensino com aspectos gerais determinados pelo modo de produção da existência humana, que, na atualidade, é hegemonizado pelo sistema do capital.

Sob a perspectiva marxista, que tomamos como referência, destacamos que a relação entre a categoria modo de produção e os fenômenos educacionais ï trabalho docente, políticas públicas, formação de professores, dentre outros ï não são estabelecidas de forma determinista e hierárquica do capital sobre a educação. Se relacionam sem determinações unilateralmente mecânicas de uma sobre a outra. Pressupomos existir uma relação em movimento, onde não há determinações impostas arbitrariamente, mas sim relações dialéticas ï contraditórias e recíprocas ï colocadas em movimento por seus agentes históricos e sua configuração de classe social.

Tendo em vista que uma das críticas mais recorrentes ao marxismo é seu suposto economicismo totalizante nas análises de qualquer fenômeno, uma das intenções subjacentes ao objetivo geral deste texto é demonstrar o trato com os elementos do real relacionados com abstrações que nos permitem explicitar que nenhum fenômeno material, tomado em sua totalidade, está isolado de uma série de relações complexas colocadas em movimento por suas contradições, em que o geral e o singular estão unidos pela via do particular. Ou seja, não se trata de desenvolver uma pesquisa para concluir que o capital determina o fenômeno unilateralmente; pelo contrário, trata-se de analisar o conjunto de elementos que configuram a totalidade, compreendendo que o específico está presente no geral e o geral está no específico, tal quais as análises que apresentamos acerca da precarização das condições de trabalho como necessidade de recomposição do capital frente à crise estrutural da atualidade.

Podemos afirmar que tais críticas ao marxismo ao mesmo tempo em que tentam refutar Marx, em boa parte das vezes, se originam em teorias do conhecimento em que ro sutil exercício linguístico põe em prática a pragmática retórica de ressignificação de conceitos. Alcançar o consenso é o fundamental, substituir sentidos e significados e a precisão de conceitos por termos vagos que 
diluem principalmente seu caráter rigorosoò (TAFFAREL; ALBUQUERQUE, 2010, p. 30). Alguns termos são modificados, o capitalismo ou o sistema do capital passa a ser concebido como m̃mundo modernoò(MÉSZÁROS, 2004); a classe social passa a ser constituída por ñdentidadesò os sujeitos históricos se tornam rãtoresò as condições objetivas de existência são substituídas por r̃cenáriosà o próprio termo classe social se dissolve em meio às questões de raça, gênero, sexualidade ou religião sem aprofundar as análises na origem e continuidade da opressão em uma sociedade de classes.

\section{Precarização das Condições de Trabalho da EF}

O sistema metabólico de controle social, o capital ï com seu inerente caráter expansionista ï subordina o valor de uso ao valor de troca das mercadorias. Como o valor de troca só se realiza quando a mercadoria é comercializada, o consumo é necessário para a acumulação de capital, portanto, produção e consumo compõem o mesmo fenômeno, onde é preciso criar a necessidade de consumir para produzir a riqueza capitalista. Porém, produção e consumo do capital estão em oposição antagônica com a produção e o consumo do trabalho. No sistema do capital, o entendimento desta tendência só pode ser amplamente compreendido se considerarmos a contra tendência específica ligada objetivamente a ela (MÉSZÁROS, 2009), polos opostos e contraditórios de um mesmo fenômeno. Em um extremo deste fenômeno, temos que a produção capitalista de mercadorias necessita consumir a força de trabalho adquirida para criar valor de troca e obter lucro ao vender sua mercadoria; no outro, para produção de sua existência o ser humano precisa consumir as mercadorias produzidas e, para isso, necessita vender a sua força de trabalho. Acontece que, em um período da história em que o desemprego estrutural e a miséria tomam proporções nunca antes experimentadas, um grande contingente de trabalhadores e trabalhadoras, sem condições de consumir, diminui o r̃írculo de consumidoresòque garante a circulação e expansão do capital, assim, a precarização do trabalho se torna condição estrutural para a manutenção das taxas de lucro capitalista da atualidade. Propagam-se as políticas de austeridade como suposta medida para contenção da crise do capital, porém, o que está em jogo é a recomposição das taxas de lucro capitalistas.

Ocorre que, "nessa fase do capital, caracterizada pelo desemprego estrutural, pela redução e precarização das condições de trabalho, evidencia-se a existência de 
uma materialidade adversa aos trabalhadores, um solo social que constrange ainda mais o afloramento de uma subjetividade autêntica" (ANTUNES, 1999, p. 131). No caso da precarização das condições de trabalho docente, em última instância, se confrontam projetos de educação também contraditórios, onde a necessidade de expansionismo do capital e recomposição de taxas de lucro geram a desvalorização da educação e, consequentemente, a desvalorização do trabalho do professorado.

Esta questão é amplamente discutida tanto no ponto de vista científico (em estudos que estabelecem críticas à atual organização escolar e também aqueles que defendem o modelo de educação hegemônico) como do ponto de vista prático (na formulação das políticas educacionais e no trabalho do professorado e do alunado). A questão a ser aprofundada aqui, diz respeito às implicações da precarização das condições de trabalho docente para a formação humana. Com este questionamento, não se trata de discutir somente os efeitos desta precarização, mas entender como se articulam os interesses da forma escolar com a formação do ser humano na concepção de educação capitalista. Trata-se, portanto, de expor as causas (que não se restringem somente ao âmbito educativo, mas efetivam-se desde a gênese do modo de produção da existência) e os efeitos na formação humana. Nesse sentido, duas questões serão tratadas prioritariamente: o financiamento da educação pública e as condições de trabalho na RMENSR.

Tratar do financiamento da educação não significa tratá-la como fim em si mesmo ou somente nos aspectos quantitativos do percentual de recursos investidos, mas como políticas públicas que expressam uma dada concepção de educação num determinado processo social. Tal como aponta Souza Júnior (2007):

\begin{abstract}
A política educacional é antes de tudo uma definição estratégica do lugar e do papel que a educação, como sistema, deve cumprir num determinado processo sócio histórico. O financiamento aparece como o modo pelo qual, objetivamente, uma sociedade, através de ações do Estado, pretende fazer com que se atinjam os objetivos estratégicos traçados. Por isso, torna-se inoperante qualquer tentativa de se compreender os problemas de fundo do sistema de educação, observando apenas o que apresentam os índices e estatísticas de investimentos em termos de percentual do PIB destinado à educação sem se considerar as profundas articulações estabelecidas entre os diversos setores (SOUZA JÚNIOR, 2007, p. 190).
\end{abstract}

Com relação ao financiamento para a educação básica, o Ministério da Educação transfere, obrigatoriamente, recursos dos seguintes programas: Merenda Escolar, Fundo de Manutenção e Desenvolvimento da Educação Básica e Programa Dinheiro Direto na Escola (PDDE), além de outros programas que destinam recursos 
somente se os sistemas de ensino ou escolas a eles aderirem. O financiamento da educação básica através do PDDE é bastante expressivo no que diz respeito à gestão da escola e dos mecanismos redefinidores do papel do Estado na atual conjuntura de crise estrutural e seus reflexos nas políticas educacionais, onde a desresponsabilização das entidades governamentais para administração dos recursos se insere na perspectiva do mercado como marco regulatório de tais políticas. Embora o discurso de desresponsabilização seja de que o controle deve ser da sociedade civil, o que se percebe é que esse controle é realizado por meio da privatização ou da constituição de uma esfera híbrida chamada ñúblico não estatalò transformando instâncias constitutivas da estrutura estatal em entidades jurídica e politicamente privadas (PERONI; ADRIÃO, 2006).

A descentralização financeira, historicamente reivindicada pelas escolas públicas, é feita através destes mecanismos privados ou públicos não estatais. $O$ PDDE, por exemplo, define como condição para o recebimento dos recursos, a existência de Unidades Executoras (UEx), que são responsáveis pelo recebimento, execução e prestação de contas dos recursos financeiros destinados às escolas públicas, tornando-se entidades de direito privado, sem fins lucrativos e que possuem representantes da comunidade escolar. Para citar um exemplo disso, os Círculos de País e Mestres se tornam UEx para gerenciar os recursos destinados diretamente às escolas, alterando sua natureza jurídica e instalando uma instituição de direito privado na esfera da gestão da escola pública e dos recursos a ela destinados. Sob a égide da participação da sociedade civil, se abre espaço para a desresponsabilização do Estado e para o fortalecimento do chamado terceiro setor (público não estatal).

Ao mesmo tempo em que o financiamento da educação básica tem essa caracterização de desresponsabilização por parte do Estado e transferindo esta incumbência para a esfera privada, as administrações estaduais e municipais também interferem diretamente na precarização das condições de trabalho nas escolas ao diminuir investimentos na escola, na carreira e na remuneração dos servidores públicos. Como em Nova Santa Rita com o Decreto Municipal № 015/10, que estabeleceu medidas visando à contenção de despesas na Administração Pública Municipal, justificando-se através de questões que vão desde a crise financeira internacional até compromissos de campanha assumidos pela atual administração. Este Decreto acaba por aumentar a precarização dos serviços 
municipais, como a educação, e a precarização do trabalho dos servidores e servidoras municipais, como o professorado, funcionários, funcionárias e equipes diretivas das escolas.

O Decreto diz que,

CONSIDERANDO, que ocorreu no primeiro trimestre uma sensível queda na receita arrecadada e que as previsões para os próximos meses indicam continuidade deste quadro de retração em relação à receita prevista; CONSIDERANDO, que ainda estão sendo sentidos os reflexos da crise financeira internacional, que acarreta diminuição da arrecadação de tributos federais, estaduais e municipais implicando na diminuição das transferências para os municípios [...].

DECRETA:

Art. 1ㅇ Ficam estabelecidas, por tempo indeterminado, as seguintes medidas administrativas básicas para racionalização, controle orçamentário e contenção de despesas no que se refere aos gastos com pessoal:

I- Proibição de pagamento de hora extra, ressalvada a prestação dos serviços considerados essenciais e mediante autorização prévia do Prefeito Municipal;

II- Suspensão de contratação ou nomeação a qualquer título, que acarrete aumento da despesa com pessoal a partir da data da publicação do presente decreto.

$[\ldots]$

IV- Proibição da indenização ao servidor de Férias ou Licença-Prêmio não gozadas, salvo em casos excepcionais devidamente justificados;

V- Suspensão da concessão de afastamento para interesse particular, que acarrete novas contratações;

VI- Suspensão da participação pelos servidores de encontros, cursos, congressos e similares;

VII- Suspensão do pagamento de diárias, ajudas de custo e outras indenizações, salvo em casos excepcionais mediante autorização exclusiva do Prefeito Municipal;

[é ]

Art. $3^{\circ}$ [é ]

II - Ficam suspensos quaisquer novos investimentos no município de Nova Santa Rita, com exceção dos necessários para o cumprimento dos percentuais mínimos estabelecidos pela Constituição Federal nas áreas de educação e saúde e daquelas obras previamente autorizadas pelo Prefeito Municipal e as já iniciadas, as quais poderão ser suspensas se assim entender a administração (NOVA SANTA RITA, 2010) [grifos nossos].

Este corte no orçamento público foi sentido durante o ano letivo de 2010. Foram seis anos sem aumento de salário do professorado, condições precárias de infraestrutura das escolas, falta de professores e professoras e de materiais didáticos para trabalhar. Com o Decreto, as principais consequências para a educação foram: nenhuma nomeação foi realizada para ocupar as vagas existentes nas escolas (aumentando o número de estágios e contratos temporários); nenhum professor ou professora pôde participar de cursos, congressos ou seminários de formação continuada custeados pela administração; nenhum investimento foi realizado nas escolas da RMENSR; os valores referentes à licença-prêmio do 
professorado vencidas desde o ano de 2009 só foram pagas em janeiro de 2011, atrasando também as outras licenças-prêmio posteriores; até mesmo a realização dos jogos escolares do ano de 2011 foi prejudicada pelos cortes no orçamento.

Estas medidas de redução de gastos com o serviço público como r̃saídaòpara a crise do capital têm sido efetivadas tanto por países do capitalismo central como dos países periféricos. Medidas de austeridade que implicam em maior precarização das condições de trabalho, perda de direitos trabalhistas e mais prejuízo à classe trabalhadora em nome da manutenção da operacionalização do sistema do capital. Porém, para adotar estas medidas é preciso convencer a classe trabalhadora que para r̃salvaròda crise do capital, todos e todas devem f̂azer a sua parteò ainda que isto signifique abrir mão de direitos trabalhistas e sociais.

O piso salarial do professorado da RMENSR é, em média, um salário mínimo e meio para $20 \mathrm{~h}^{1}$, naqueles que se enquadram na categoria Professor Ensino Fundamental ï séries finais ï nível II, de acordo com o Plano de Carreira do Magistério Municipal (PCM). Abaixo, apresentamos um quadro referente à carga de trabalho do professorado de EF que contribuiu neste estudo².

\begin{tabular}{|l|c|c|c|c|}
\hline $\begin{array}{c}\text { PROFESSO } \\
\mathbf{R} \\
\text { PROFESSO } \\
\text { RA }\end{array}$ & $\begin{array}{l}\text { IDADE } \\
\text { (anos) }\end{array}$ & $\begin{array}{c}\text { REGIME DE } \\
\text { TRABALHO } \\
\text { RMENSR }\end{array}$ & $\begin{array}{c}\text { REGIME DE } \\
\text { TRABALHO } \\
\text { OUTROS }\end{array}$ & $\begin{array}{c}\text { TOTAL DA } \\
\text { CARGA DE } \\
\text { TRABALHO }\end{array}$ \\
\hline Professora A & 44 & $20 \mathrm{~h}$ & $30 \mathrm{~h}$ ï Academia & $50 \mathrm{~h}$ \\
\hline Professora B & 42 & $20 \mathrm{~h}$ & $20 \mathrm{~h}$ ï Sapucaia & $40 \mathrm{~h}$ \\
\hline Professor C & 30 & $20 \mathrm{~h}$ & $\begin{array}{c}28 \mathrm{~h} \text { ï Sapucaia } \\
10 \mathrm{~h} \text { ï Canoas }\end{array}$ & $58 \mathrm{~h}$ \\
\hline Professor D & 29 & $40 \mathrm{~h}$ & - & $40 \mathrm{~h}$ \\
\hline Professora E & 26 & $20 \mathrm{~h}$ & - & $20 \mathrm{~h}$ \\
\hline Professor F & 31 & $20 \mathrm{~h}$ & $\begin{array}{c}20 \mathrm{~h} \text { ï Novo } \\
\text { Hamburgo }\end{array}$ & $40 \mathrm{~h}$ \\
\hline Professor G & 34 & $30 \mathrm{~h}$ & - & $30 \mathrm{~h}$ \\
\hline Professor H & 31 & $20 \mathrm{~h}$ & $\begin{array}{c}24 \mathrm{~h} \text { ï Rede } \\
\text { Estadual de Ensino } \\
21 \mathrm{~h} \mathrm{ï} \mathrm{Clínica}\end{array}$ & $65 \mathrm{~h}$ \\
\hline
\end{tabular}

Quadro 1: Regime de trabalho do professorado na RMENSR e em outros espaços

\footnotetext{
${ }^{1}$ Tomamos por base o salário mínimo nacional do ano de 2010 , estipulado em $R \$ 510,00$.

2 Todas informações expostas são referentes ao ano de 2010, em que foram coletadas as informações.
} 
Do professorado total que compõe o estudo, três mulheres e cinco homens, com idade entre 26 e 44 anos, a maior parte (75\%) tinha uma jornada de trabalho igual ou superior à $40 \mathrm{~h}$ semanais, dos quais, apenas um, tinha estas $40 \mathrm{~h}$ na RMENSR. O professor $\mathrm{G}$ tinha uma carga de trabalho de 30h por ser estagiário no município, além da disciplina de EF nas séries finais do ensino fundamental, trabalhava, no período da tarde, com alguns projetos desenvolvidos pela Secretaria Municipal de Educação, Esporte e Cultura ou pela própria escola.

A principal razão para que o professorado busque uma carga horária de $40 \mathrm{~h}$ ou mais, segundo os próprios relatos, é o baixo nível do salário (piso e gratificações) que, insuficiente, obriga o professorado a ampliar sua jornada de trabalho em outros municípios, em outras escolas ou mesmo fora do campo escolar. A metade do professorado $(50 \%)$ trabalhava em outras redes de ensino da região metropolitana de Porto Alegre e outros trabalhavam também fora da área escolar (academia e clínica de reabilitação).

Esta carga excessiva de trabalho é motivo de preocupação por parte do professorado, como relata o Professor C:

Tu não tem ideia do que tu é sugado quando tem mais de 60 horas semanais e tem que dar conta de caderno, de prova, de coisas que tu não tem na faculdade. Não tem essa noção na faculdade, eles não te passam isso aí [...] E tem que ser um trabalho bom, porque se tu te enrolar, tu mesmo vai chegar no final do ano vai estar estressado porque não tá dando conta, então tu tem que se organizar (Professor C, 2010) [grifos nossos].

Esses problemas fazem com que o professorado expresse sensações de insatisfação com o trabalho, querendo diminuir a carga ou até mesmo abandonar o trabalho na escola, dado o nível de intensificação e de exigências que o professorado deve cumprir. Ao realizarmos o acompanhamento e a entrevista com a Professora $\mathrm{E}$ ela relatou estar à procura de outros campos de trabalho fora da área, conforme sua fala: m̃ão pego outro serviço na área de EF, porque eu quero deixar a EF. Não estou mais aguentando!ò (Professora E, 2010). No ano de 2011, ao retornarmos à escola para dar sequência ao trabalho de campo, a Professora $E$ já havia pedido exoneração do município e estava trabalhando em outra área, como comissária de bordo em uma companhia aérea.

Ao dialogarmos com esta professora, questionamos sobre as dificuldades enfrentadas na escola e, ao responder à questão, observamos que o seu relato é bastante expressivo de como o trabalho na escola centraliza a própria vida do 
professorado que se desdobra durante a semana entre deslocamentos, horários, planejamentos, além de outras questões que tornam o trabalho na escola bastante desgastante.

[...] uma das maiores [questões] é a locomoção [...] Os horários dos ônibus nunca fecham com os horários da escola. Ali onde eu moro tem que pegar um ônibus até o Centro e do Centro vir pra cá. Aí, eu tô pegando carona com a minha colega. Daí eu tenho que dormir fora de casa na minha vó, então é toda uma complicação, fica cansativo, sabe? Chega uma hora que tu fica assim: ñAi, não aguento mais ter que ir pra lá por causa disso!ò Outra dificuldade, eu até poderia reclamar dos materiais, mas eu me viro com o que eu tenho tranquilamente. Claro que eu me lembro da minha EF na escola, eu estudei em escola particular, eu podia fazer exercício em dupla, cada dupla com uma bola, de vôlei, futsal, de basquete, o que eu quisesse... Vinte bolas. Aqui não. Eu tenho quatro, três e eu tenho que me virar com grupo de 30 alunos. E é isso aí pro ano inteiro, tem que durar dois, três anos [...]. Foi um dos principais motivos que me fizeram buscar outra área pra trabalhar, além da locomoção. Claro que a gente fica cansado, o aluno fica gritando no ouvido, vai dar aula no frio, vai dar aula no calor, é complicado a questão climática, não tem ambiente fechado, mas é o que a casa oferece! (Professora E, 2010).

As condições infraestruturais das escolas também são motivo de crítica por parte do professorado e do alunado, pois não possibilitam o desenvolvimento das aulas da maneira como planejam. A reflexão que o Professor $D$ esboça sobre 0 trabalho do professorado na escola e das implicações da falta de condições estruturais nos dá pistas do esgotamento das possibilidades criativas do trabalho pedagógico e das formas de disciplinamento existentes no sistema educativo para que o professorado e o alunado adaptem-se à perspectiva hegemônica da formação escolar: ñ̀̀s vezes tu vem com uma ideia, mas vai parando naquela hierarquia, naquela coisa que vai te podando, vai te podando... Daqui a cinco, seis anos tu vai estar assim: 'Ah, quer saber, deixa assim, vamos tocar assim'ò (Professor D, 2010).

Durante o acompanhamento do trabalho pedagógico percebemos as dificuldades com relação à estrutura que o professorado e o alunado enfrentam no seu trabalho, registramos assim as condições infraestruturais das escolas: r̃das seis escolas de ensino fundamental do município, somente três delas possuem quadras esportivas ou algum espaço adequado para as aulas de EF; na EJA, que se realiza no turno da noite, não há iluminação no pátio e nem nas quadras esportivas impossibilitando trabalhar fora da sala de aulaò(DIÁRIO DE CAMPO, 21 de junho de 2010); na escola em que o professor G trabalha ñão tem quadra esportiva e nem espaço adequado para a realização das aulas, que são desenvolvidas no meio dos prédios de salas de aulaò(DIÁRIO DE CAMPO, 22 de junho de 2010); na escola em 
que trabalha o professor $\mathrm{H}$ : m̃ão possui quadra, a aula se realiza em um pátio atrás da escola que tem 2 goleiras, piso de chão batido com mato no meio do campoò (DIARIO DE CAMPO, 29 de setembro de 2010); a escola em que trabalha a Professora A:

[é ] não possui quadra, tem um campo de chão batido com duas goleiras e amplo espaço. A aula acontece nos corredores entre as salas de aula e um espaço coberto utilizado como quadra em dias de chuva. Uma corda entre dois pilares de um prédio é a rede do jogo de vôlei. Um espaço coberto de aproximadamente $6 \mathrm{~m} \times 6 \mathrm{~m}$ é utilizado como quadra para o futebol. Seguidas vezes, as atividades são interrompidas para que a bola, suja de barro, seja limpa com um pano e depois se reinicie a aula (DIÁRIO DE CAMPO, 29 de março de 2010).

Em meio à falta de condições adequadas para o trabalho, o professorado se obriga a adaptar formas de trabalho e materiais didáticos para utilizar. Ou ainda, como relata a Professora $B$ dizendo que r̃se tu não inventar, tu não trabalha. Às vezes não tem bola, não tem recurso nenhum!ò (ENTREVISTA Professora B, 12 de abril de 2010)

Tem uma coisa, mas não depende da escola, depende do município, a construção da quadra, uma quadra ou um ginásio alguma coisa assim, mas fora isso a gente adapta, tudo a gente adapta, se não dá pra fazer assim a gente trabalha com o que tem. Não tem isso. A gente vai trabalhar com aquilo da melhor maneira possível (Professora A, 2010).

O Professor $\mathrm{H}$ aponta que os impactos da precarização das condições de trabalho na escola incidem diretamente na formação do alunado:

O problema é que assim, eu não tenho muita versatilidade em trabalhar com determinados esportes porque eu não tenho infraestrutura pra isso, a gente foi ali no campo e tu notou que a gente não tem espaço pra basquetebol, então fica muito empírico eu falar de regras, falar de jogadas, falar de jogadores importantes se eles não têm a vivência prática, o máximo que eu tenho é uma bola de basquete que eu levo pra sala de aula e mostro: ñDlha, esse é o peso da bola, é assim que funciona o jogoò(Professor H, 2010).

O alunado também expressa sua insatisfação com as condições estruturais das escolas do município, quando perguntamos quais são os aspectos negativos da escola em que estudava, a maior parte das respostas (34\%) tinham o sentido de afirmar que as escolas não apresentam condições estruturais adequadas, falta de materiais, espaços (quadras esportivas, refeitório, cobertura do pátio etc.) e falta de professorado. Como podemos visualizar no gráfico a seguir: 


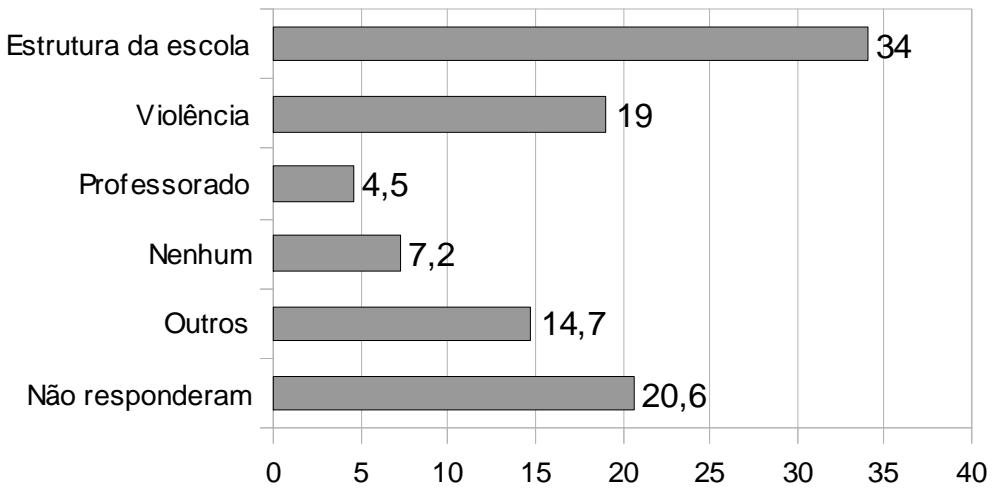

Figura 1: aspectos negativos da escola onde estuda - respostas do alunado (\%)

Embora estejamos trabalhando com as consequências ou os efeitos da precarização da escola capitalista, no que diz respeito ao financiamento e garantia de condições de trabalho adequadas, entendemos que o marco crítico deva se aprofundar na gênese que vai colocar a escola nestas condições. Não se trata somente de aumento de investimentos, pois, nas condições em que os recursos são investidos, não possibilitam soluções para os problemas referentes à qualidade do ensino.

Com relação às questões referentes às condições de trabalho na RMENSR, podemos sintetizar da seguinte forma:

a) Há uma precária infraestrutura nas escolas para as aulas de EF: somente três das seis escolas de séries finais do ensino fundamental possuem quadras esportivas ou espaços adequados para a realização das aulas de EF e/ou prática de esportes. Na escola municipal que oferta a EJA, embora possua uma quadra esportiva, não há iluminação para realizar as atividades no período noturno, impossibilitando de utilizar este espaço para a EJA;

b) Há uma carência de materiais didáticos para as aulas de EF: segundo os relatos do professorado; eles têm que ñnventarò t̃rabalhar com o que temò radaptarò ou r̃driblarò as dificuldades para conseguirem trabalhar. Muitas vezes utilizando o discurso de reutilização de materiais recicláveis para desenvolver alguns conteúdos de suas aulas;

c) Há uma crescente intensificação do trabalho do professorado decorrente das condições de remuneração e trabalho: além do baixo salário, são seis anos sem aumento salarial (desde outubro de 2006), faltam professores e professoras nas escolas, o professorado se obriga a trabalhar $40 \mathrm{~h}$ ou mais junto a outras redes de 
ensino, são frequentes os atrasos da administração municipal referentes ao pagamento das obrigações do PCM (por exemplo, a licença-prêmio atrasada por dois anos), observou-se um desgaste com equipes diretivas e falta de estímulo para a categoria;

d) Não há incentivo para a formação continuada do professorado: está previsto no Decreto 015/2010 a suspensão da participação dos servidores e servidoras municipais em congressos, seminários, cursos e outros. Também, o PCM (Lei Municipal 695/2004), ao prover o nível III, que atinge aquele ou aquela que realizar curso de pós-graduação, independentemente qual, especialização, mestrado ou doutorado como mais elevado da carreira, não estimula à continuidade da formação do professorado na RMENSR;

e) É limitado o acesso ao conhecimento por parte do alunado: consequência das condições de infraestrutura e investimento nas escolas, o alunado é cerceado do acesso às diferentes manifestações da cultura corporal, ainda que se busque adaptar as condições para vivenciá-las.

\section{CONSIDERAÇÕES FINAIS}

Mesmo pontuando consequências da precarização das condições de trabalho é preciso relacioná-las às causas que originam tais determinações. Temos desenvolvido a ideia que a escola capitalista precisa, ao se pautar pela lógica de mercado na formação, dessas características de precarização do trabalho. Isso, sobretudo, porque o mercado exige uma formação flexível e polivalente, com competências para solução de problemas e adaptável a situações decorrentes da instabilidade e volatilidade do atual quadro de desemprego estrutural.

É ilusório, no entanto, pensarmos que o problema da educação pública reside na falta de investimentos em virtude da crise do capital ou por dificuldades econômicas do Brasil. Oque se expressa no real e nas políticas públicas são projetos distintos de sociedade em que se privilegia a destinação de recursos para a manutenção e recuperação do capital financeiro especulativo dos bancos, para o financiamento do agronegócio e do mercado imobiliário, além do escoamento de verbas públicas para a realização dos megaeventos esportivos dos próximos anos. Para ilustrar esta afirmação, a Auditoria Cidadã da Dívida aponta que o orçamento geral da União aprovado para o ano de 2011, destinava 45,05\% dos recursos do PIB 
para o pagamento da dívida pública - aproximadamente 708 bilhões de reais -, enquanto que para a educação foram destinados somente $2,99 \%$ do PIB (FATTORELLI; ÁVILA, 2012). Demonstramos essa questão através da destinação de quase a metade dos recursos do PIB brasileiro para pagamento da dívida pública e também da forma como se operam mecanismos híbridos de controle privado sobre recursos públicos.

Como projetos de sociedade em disputa, a escola desempenha um papel de significativa responsabilidade no sistema do capital, tanto quanto a produção de mercadorias, a escola é parte importante na formação dos sujeitos históricos, únicos capazes de transformar a realidade. Assim, a garantia da reprodução do modo de produção do capital passa também pela direção dos processos educativos da sociedade de classes, daí que a educação deve ser pensada para formar indivíduos "domesticados", além de não possibilitar o acesso a todo conhecimento produzido historicamente e em condições adequadas de apropriação pela classe trabalhadora.

Investigar a relação entre o singular e o geral é percorrer caminhos permeados por contradições, entre polos contrários que se determinam reciprocamente e que constituem o particular como mediação em movimento. Nesta análise que procedemos, a relação entre a singularidade da atividade do professorado na escola e o modo de produção como geral manifesto na totalidade dos fenômenos materiais, identificam-se particularidades históricas das relações de produção destrutivas, tal como a precarização da educação e das condições de trabalho nas escolas.

$\mathrm{Na}$ introdução do livro "Contribuição à Crítica da Economia Política", escrita em 1859, Marx (2008) elabora a análise da economia política e a forma de apropriação da realidade pelo pensamento, através do método do conhecimento científico em que não se pode partir de uma abstração geral imediatamente dada (como a população para analisar a economia política, por exemplo), pois esta seria uma representação caótica do todo e que levaria a representações mais abstratas ainda. Embora, neste texto, Marx não explicite a relação entre singular e geral, ao sistematizar o caminho científico para conhecer o real, a análise do fenômeno (ou sua decomposição em partes) vai delimitando relações mais simples e determinantes que, na síntese (ou a recomposição da totalidade) o todo vai se tornando concreto constituído por múltiplas determinações, ou seja, "unidade do diverso" (MARX, 2008, p. 256). É através da relação entre o singular e o geral, pela 
via da mediação particular, que se consegue alcançar esta compreensão da realidade em sua totalidade, tal qual intentamos proceder neste estudo em relação à atividade do professorado de EF na escola e as determinações recíprocas com o modo de produção da existência.

\section{REFERÊNCIAS}

ANTUNES, Ricardo. Os Sentidos do Trabalho: ensaio sobre a afirmação e a negação do trabalho. São Paulo: Boitempo, 1999.

FATTORELLI, Maria Lúcia; ÁVILA, Rodrigo. Os Números da Dívida. Auditoria Cidadã da Dívida, 2012. Disponível em: http://www.auditoriacidada.org.br/wpcontent/uploads/2012/04/Numerosdivida.pdf. Acesso em: 26 de janeiro de 2013.

MARX, Karl. Contribuição à Crítica da Economia Política. $2^{\mathrm{a}}$ edição. São Paulo: Expressão Popular, 2007.

MÉSZÁROS, István. Para Além do Capital. 3ª reimpressão. São Paulo: Boitempo, 2009.

. O Poder da Ideologia. São Paulo: Boitempo, 2004.

NOVA SANTA RITA. Decreto № 15/2010. Medidas visando contenção de despesas. Nova Santa Rita, 5 de abril de 2010.

PERONI, Vera; ADRIÃO, T. Mudanças na configuração do Estado e sua influência na política educacional. In: PERONI, V.; BAZZO, V.L.; PEGORARO, L. (Orgs.). Dilemas da educação brasileira em tempos de globalização neoliberal: entre o público e o privado. Porto Alegre: UFRGS, 2006, p. 11-23.

SOUZA JÚNIOR, Justino. Financiamento da Educação, Fundo Público e Economia na Periferia do Capitalismo Mundializado. In: FRIGOTTO, G.; CIAVATTA, M.; RAMOS, M. (Coord.). Seminário de Pesquisa: trabalho de políticas públicas de educação: Projetos em disputa na sociedade brasileira. Rio de Janeiro: EPSJV, 2006, p. 181-197.

TAFFAREL, Celi; ALBUQUERQUE, Joelma. Epistemologia e Teorias do Conhecimento em Educação e Educação Física: reações aos pós-modernismos. Revista Filosofia e Educação (Online), Revista Digital do Paideia, Uberlândia, Volume 3, Número 2, Outubro de 2010 ï Março de 2011. 
THE RELATIONS BETWEEN THE SINGULAR AND THE GENERAL IN THE DETERIORATION OF PHYSICAL EDUCATION WORK CONDITIONS AT SCHOOL

\begin{abstract}
:
The objective of this paper is to go deeper in the analysis about the deterioration of Physical Education (PE) work conditions at school. Through a case study conducted in the municipal schools at Nova Santa Rita, we seek to develop the relationship between the singular and the general, by the way of particular mediation, to understand the reality of the phenomenon in its totality, in terms of the PE teachers activity at school and the reciprocal determinations with the modes of production of life.
\end{abstract}

Keywords: Physical Education. Work conditions. School.

\title{
LAS RELACIONES ENTRE LO SINGULAR Y LO GENERAL EN LA PRECARIZACIÓN DE LAS CONDICIONES DE TRABAJO DE LA EDUCACIÓN FÍSICA EN LA ESCUELA
}

\section{RESUMEN:}

El objetivo de este texto es profundizar el análisis sobre la precariedad de las condiciones de trabajo en la Educación Física (EF) en la escuela. A través de un estudio de caso realizado en las escuelas de la ciudad de Nova Santa Rita, buscamos desarrollar la relación entre el singular y lo general, por medio del particular, para comprender la realidad del fenómeno en su totalidad, en relación a la actividad del profesorado de EF en la escuela y las determinaciones reciprocas con el modo de producción de la existencia.

Palabras-clave: Educación Física. Condiciones de Trabajo. Escuela.

\section{Endereço para correspondência:}

Isabella Filippini

E-mail: bellafilippini@gmail.com 